\title{
SPECIAL ISSUE EDITORIAL
}

\section{Anatoly OLEKSIYENKO, Rui YANG}

\section{Nix the BRICs? Competitive and Collaborative Forces in the Ostensibly "Blocalized" Higher Education Systems}

Comparative studies on higher education in the BRICs have been few and far between. There are even fewer scholarly publications in the field that have engaged all five countries: Brazil, Russia, India, China, and South Africa. Some scholars follow the original abbreviation coined by Tim O'Reilly, an influential Goldman Sachs economist, that included the first four countries, the "BRICs," and some others, like us, follow the subsequent political developments of a larger bloc that includes South Africa. While various research teams investigate various aspects of higher education development, this editorial focuses on the relevance of what could be termed as "blocalization" in higher education from the viewpoint of internationalization and emerging competitive-collaborative perspectives in the BRICS.

In the early 2010s, two scholars on opposite coasts of the US, Martin Carnoy in Stanford and Philip Altbach in Boston College, each teamed up with their peers in Brazil, Russia, India, and China to shed light on transformations in the higher education systems of the multinational bloc (see Altbach, Reisberg, Yudkevich, Androushchak, \& Kuzminov, 2013; Carnoy et al., 2013). Their studies revealed a number of seemingly shared challenges, e.g., massification, systemic resource asymmetries, quality assurance problems, shortcomings in academic governance and the academic profession. However, the studies also identified some unbeatable advantages of the BRICs higher education systems, including a desire by the national governments to invest more in national flagship institutions, in order to make them engines for global competition. These advantages stood out in stark contrast at a time when Western competitors were struggling with the fallout of the global financial crisis, and introducing 
neoliberal policies that reduced public subsidies for higher education.

In their most recent article, Nix the BRICs: At Least for the Higher Education Debate, Altbach and Bassett (2014) urged research communities to honestly admit the limited extent to which bloc-related discussion was relevant or important for the field of higher education. The authors argued that the initial attraction of higher education scholars to the BRICs as a bloc was largely driven by "marketing artifice" created by an influential investment banking corporation, rather than by any serious factors underpinning the research or development needs in higher education. Likewise, the creator of the acronym, Tim O'Neill, recently changed his position on the relevance of BRICs as a global player, moving on to consider other cross-continental alliances that he believed to be changing the rules of the game in the global economy (see Altbach \& Bassett, 2014, p.2). Furthermore, Altbach and Bassett reasoned that bloc-based comparative work actually makes little sense and is of limited value for comparability objectives or understanding the complexity that exists in the higher education environments of the individual BRICs members. The diversity and incompatibility of political, economic, and cultural predispositions essentially nullifies all conclusions with regard to future discussions within the bloc's higher education sector, argued the researchers.

Indeed, does it make sense to investigate the "blocalization" of higher education, in general, and in the questionable construct presented by the BRICS, in particular? The guest editors of this issue had doubts similar to those discussed by Altbach and Bassett. However, the editors concluded that the topic of internationalization and partnerships in the multinational bloc was worth exploring. First of all, many issues related to "blocalization" have remained understudied in higher education. Secondly, the theme of international academic collaborations has remained scantly covered in the literature. The previous studies argued that globalization affected each country and university, whether they admitted this or not, and that many countries and universities had adopted internationalization as a strategic response to globalization by increasing cross-border flows of ideas, students and resources. However, the higher education literature has revealed little about partnership policies and challenges in the emerging global political and economic powers. Moreover, very little was discussed about the BRICS' aspirations and capacities to change paradigms of international partnership-building in general, and in the member countries in 
particular.

The latter was particularly driving our enthusiasm for the study, as the BRICs had announced a quest for regional and global leadership in higher education. In fact, BRICS member countries were argued as having sufficient ambitions and capacities to become global economic competitors. China and Russia also became more outspoken about their soft power policies, although the same could not be said about the other three members. Russia followed China in the institutional differentiation strategy and launched the 5-100 project to propel at least five national universities up the ladder of top-100 positions in the global ranking tables. Russia also played a major role in lobbying the BRICS university ranking table, and indeed succeeded in promoting the QS commercial project that separated the bloc's university positions from those of more advanced competitors in the West, and thus created more prominence for the "blocalized" universities. Despite all these developments, the comparability of internationalization policy frameworks was put into question by the end of this special issue, as Russia became increasingly isolated by $\mathrm{G} 7$ governments in response to its annexation of Crimea and political meddling in Ukraine. The events had a negative projection on the BRICS ambitions of gaining more global power. In view of the revisionist trends within Russia, the guest editors were feeling the increasing sense of irrelevance that was noted by Altbach and Bassett, and at some point considered discontinuing the project.

Meanwhile, the emerging contributions deserved attention. The comparison of internationalization policies, made it possible to see the extent to which the bloc members had capacity to develop unifying perspectives on their soft power diplomacies. Collaborations inside the bloc, as well as with neighboring countries, seemed to be the logical focus of an inquiry into coordinative efforts toward the goal of enhanced global impact. However, given that, the "blocalized" intellectual project made little sense if its members were unable to agree on the values of global neighborhoods, peace and order, the academic collaborations would be inevitably strained by political challenges. By examining differences in internationalization policies and comparing higher education partnerships in BRICS higher education systems, this issue had a chance to shed light on bloc-based tensions and question the bloc's innovative contributions to cross-border higher education.

Reflective of the tensions and dynamic time in which they were produced, the 
papers in this issue indeed provide valuable insights into the challenges of leadership when the aspirants move from the periphery to the center of the global higher education framework, which is often construed to benchmark competitive and powerful university positions. As the papers presented here show, Brazil, China, India, Russia, and South Africa all hold leadership aspirations, particularly given that they themselves, and others around them, view them as important economic and political players. However, the important others (e.g., development banks, foreign governments and private stakeholders) overemphasize the global competition, and underemphasize the burden of homework that these countries have to do on improving the quality of human and institutional agency, including academic governance, autonomy, and access to high quality higher education (Altbach \& Bassett, 2014). Crucially, in light of these important elements, there is a danger of overestimating each BRICS member's capacities and desire to deal with domestic issues, while at the same time taking on international commitments.

Internationalization legacies can play an incentivizing or a disempowering role in national higher education reform efforts, as well as in shaping cross-border relations. As noted by Oleksiyenko, the re-Sovietization and recourse to imperial ambitions in Russia has entangled universities in political agendas that are neither appealing to local scholars, nor to their counterparts abroad. Sá and Grieco's Brazilian case, and Yang and Xie's paper on China, make the differences in the path-dependence challenges in the BRICS seem even more complex: While Brazil struggles with complacency, China deals with an excessive sense of "needing to catch up," which drives reform fatigue. While the Indian case by Varghese, and the South African case by Rensburg, Motala, and David, somewhat converge around notions of post-colonial dependencies, they also diverge with regard to national aspirations for regional leadership. These cases stand in stark contrast to the account of Russian foreign policies that try to resurrect imperial legacies and colonize geopolitical neighborhoods.

Ironically, - and as Yang and Xie remark, inappropriately-most BRICS countries tend to prioritize partnerships with Western universities (as evidenced by trends in governmental investments in cross-border higher education and mobility of local students) at a time when the governments want to position national interests as superior to global agendas. Understandably, neither the local elites' educational constructs for their offspring, nor reform-oriented domestic 
labor markets, can refute the advantage or prioritization of Western education at a time when global competitiveness is defined by Western economies. Furthermore, BRICS countries fail to provide truly competitive cultural packaging and positioning of local products in global domains, when individual freedoms are not at the core of these packages.

However, there are some hopeful indications of progress. As the BRICS higher education systems improve the quality of their higher education institutions, while learning from their competitors abroad, they are able to increase the number of inbound students from less developed countries in their regions. Moreover, BRICS countries have been seeking to integrate academic returnees, as well as recruit a larger number of foreign teachers. While there may be a human capital imbalance emerging from this trend (e.g., local brain drain substituted with less competitive brain gain), it should also be recognized that south-south collaborations have flourished, promising to turn the numerical changes in the cross-border mobility into changes in quality in short order. China is leading in turning the promise into reality by recruiting the best scientific talents in its knowledge diasporas from the Ivy League institutions of North America.

The five papers offered in this issue present a variety of emphases, which supplement, rather than supplant each other. As Varghese notes, the world of higher education is full of various collaborative arrangements, and the move from political to economic imperatives in socioeconomic systems also implies a shift in the nature of collaborative choices and strategies. Changes did not only occur in relations between developed and developing countries, but also in relations among developing countries, and the latter have become even more significant. While most of the literature looks at the north-south, or east-west dichotomies of collaborations, the BRICS cases present an interesting opportunity to not just examine the nature of developing country collaborations, but to identify and analyze those that allow the developing countries to acquire more ambition, power and resources and to make the transition from the developing to the developed world.

Nonetheless, given the different aspirations and capacities for global outreach, the five BRICS countries can hardly claim that they can make a paradigm shift in the conceptualization of international higher education partnerships as a transcontinental multinational bloc. The vision and creativity necessary for the 
conceptualization of global roles, as well as institutional leadership for advancing these roles, are weak. In that regard, no revolutionary changes that would propel BRICS as a global pacesetter can be foreseen. However, it is still important to explore the changes in the partnership building strategies of these global contenders, regardless of whether they are considered a bloc or not. In particular, it might be interesting to compare the development of international partnership building at the level of individual academics, and see how these partnerships influence the national flagships of higher education with regard to adopting global trends, as well as creating impact on local reforms. This may be a deserving subject for a subsequent comparative study.

\section{References}

Altbach, P. G., \& Bassett, R. M. (2014). Nix the BRICs: At least for the higher education debate. International Higher Education, 77, 2-4.

Altbach, P. G., Reisberg, L., Yudkevich, M., Androushchak, G., \& Kuzminov, Y. (Eds.). (2013). The global future of higher education \& the academic profession: The BRICs and the United States. Basingstoke, England: Palgrave Macmillan.

Carnoy, M., Loyalka, P., Dobryakova, M., Dossani, R., Froumin, I., Kuhns, K., ... \& Wang, R. (2013). University expansion in a changing global economy: Triumph of the BRICs? Stanford, CA: Stanford University Press. 